Research Article

\title{
Gamification and Machine Learning Inspired Approach for Classroom Engagement and Learning
}

\author{
Kavisha Duggal $\mathbb{D}$, Lovi Raj Gupta, and Parminder Singh \\ Lovely Professional University, Jalandhar, Punjab, India \\ Correspondence should be addressed to Kavisha Duggal; dhillon.kavisha89@gmail.com
}

Received 3 April 2021; Revised 19 April 2021; Accepted 24 April 2021; Published 8 May 2021

Academic Editor: Dr. Dilbag Singh

Copyright (c) 2021 Kavisha Duggal et al. This is an open access article distributed under the Creative Commons Attribution License, which permits unrestricted use, distribution, and reproduction in any medium, provided the original work is properly cited.

\begin{abstract}
Technology has enhanced the scope and span of the teaching and learning process but somehow it could not enhance the self-motivation and engagement among the students to the same scale. The lack of self-motivation and intermittent engagement is one of the prime challenges faced by educators today. Perplexing tasks for the faculty are to embroil students during the lecture. This work paves new ways to scale up the enticement using artificial intelligence and machine learning. The intelligent framework proposed here is built on yet another novel methodology used globally for user engagement and is termed gamification. The primary objective of the present research work is to negate the issue of disengagement by designing and implementing a gamified framework on 120 students from higher education that will include student engagement, enticement, and motivation. Generally, mechanisms are designed for specific courses, whereas the gamified system proposed is an open-ended method irrespective of course and the program being studied, and this framework has endeavored on multiple courses. To enhance the utility of the gamified framework, ANFIS model is utilized for smart decision-making concerning rewards distribution that is directly proportional to the number of coins gained by the students. As an outcome, better participation of a group of students under the proposed intelligent gamified system is reported as compared to the control group thus endorsing the success of the model.
\end{abstract}

\section{Introduction}

Gamification is one of the prominent research fields that has sprung up in the recent years, but still has a lot of unexplored areas $[1,2]$. Greater attention is required to integrate concepts of gamification and educational games to enhance the latest elements and use of handheld devices in the classroom to upgrade the traditional learning framework [3]. Elaborate use of game elements in specific educational contexts makes the concept of gamification more engaging; however, strong technical support is required for controlled implementation and evaluation of gamification in the field of education [4]. To support learning and teaching goals, a gamified educational system [5] can be viewed as the design scheme of using game design elements in contexts of education [6]. The process of gamification involves the usage of various software, video games, or computers, and it is much more beyond this [7].

Gamification is a vast concept that consists of game design elements, mechanics, and dynamics. Along with this, it is a combination of engagement and progression loop. Educational organizations are moving toward e-learning. They are providing online courses via Massive Open Online Courses (MOOCs) and material for their students. It has become a huge challenge for educational organizations to retain the students associated with their organization. Gamification may be used to create a bridge between education organizations and their students. This will help them to provide a more captivating environment to students that help the organizations to increase their productivity and user 
engagement on their portal $[8,9]$. The prompt development of mobile technology is shifting the paradigm from e-learning to mobile learning [10].

1.1. Problem Identification. Although gamification has provided a significant platform to be deployed in several fields, it is still an open quest to implement successfully [11]. An adaptive analysis needs to be done to understand the fact that does gamification work. Therefore, it becomes crucial to design the gamified process very carefully. Missing of required game design elements may result in unexpected output from gamification. As we are dealing with generation- $\mathrm{z}$ students, they are losing their interest in the traditional education system to enhance new learning experiences. By analyzing the sensitivity of students toward their study and the advantages of gamification technology, a need of involving new gamification-oriented engagement technology in the education system has been realized.

1.2. Motivation. As gamification is an emerging technique, it motivates to enhance the traditional learning methods $[12,13]$. Gamification has also contributed to the development of the students suffering from several psychological issues such as dyslexia, depression, stress, anxiety, and many others [14]. Gamification is also used with virtual simulations to increase learning exposures that help students to gain competency and confidence. Moreover, gamification in environmental education has been implemented for social causes [15]. A mobile-based education system was developed in the form of a game to increase user awareness and participation to save the environment.

1.3. Contribution. By analyzing the above-discussed issues, a novel gamification technology-oriented education framework is proposed to motivate the students for their studies. Gamified application is only complete when it has its welldefined components, mechanics, and dynamics [16]. A complete element-based pyramid of classroom learning is presented in Figure 1. The primary factors such as valuable structure, meaningful choices, and quantifiable metrics are also included in the gamified framework to complete the process of Gamified Educational System (GES). In recent years, machine learning has shown remarkable development in terms of analyzing data and predictions. It plays a major role in the field of education for analyzing the performance of the students by identifying the early disengagement factors [17].

The size and quality of data are two important factors for the prediction based on any machine learning technique. The data set involved for predictive analysis should be more indicative, which leads to the more precise predictions they are expected to make [18]. In this proposed study, an attempt of combining the most influential parameters of machine learning and gamification is made to enhance the effectiveness of the education system. The contribution of the proposed system is as follows:

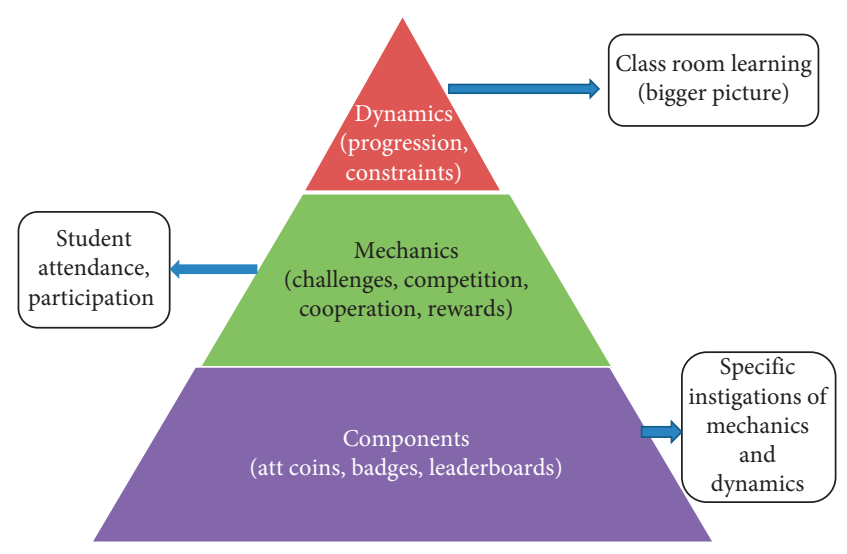

FiguRE 1: Element pyramid of classroom learning.

(1) Student's engagement and regularity to classes will be examined through attendance in a gamified framework

(2) Examination of the overall performance of students in the gamified framework on a weekly basis

(3) The microlevel study elaborates the student's participation with respect to different attributes of the gamified framework

(4) Machine-learning-oriented reward-based decisionmaking for the enhancement of classroom engagement

1.4. Article Structure. This structure of the article is as follows: some of the imperative work related to gamification and machine learning is discussed in Section 2. The solution concerning the abovementioned proposed objectives is thoroughly explained in Section 3. The evaluation of the proposed gamified framework and calculated statistical outcomes are discussed in Section 4. At last, Section 5 closes the article by discussing some of the conclusive remarks concerning the proposed solution related to the Gamified Education System (GES).

\section{Literature Review}

Some of the imperative work related to gamification and machine learning in the domain of education is discussed in this section. The review of the literature for the proposed solution is presented by dividing it into two sections as follows:

2.1. Gamification in Education. There exists a lack of motivation among students; they are not highly motivated to come regularly for fulfilling the attendance requirement. There is a need to design an educational tool that has high engagement and motivational techniques as commercial or online games are bestowed [19]. Gamification is a novel concept that has caught the attention of academics; researchers have gradually increased in the field of education [20]. Games can play a vital role to use education as a medium to talk about energy issues. Energy education, social 
interaction, and energy conservation have been used in gamification to enable support for smart grid technology. Intrinsic and extrinsic motivation is clearly explained. Games are a good example of intrinsic motivators [21]. Gamification helps to increase user engagement toward applications. Authors have introduced the concept of interactive mobile applications carrying the features of gamification. A simple and convenient application was developed for users to report road accidents in the interactive mode of the gaming layer [22]. Online education has become one of the largest demands in the field of Internet as well as in education. Online platforms provide a typical scenario of providing valuable content online on a web portal. The author has analyzed the existing problems of interaction design for online education and has introduced the concept of gamification to improve the overall utilization rate of user experience [23]. The gamified approach involves various fun-based games and makes it a useful learning strategy for the easy and successful implementation of programming topics [24]. The concept of gamification is entirely different from game-based learning. Gamification can be used in broader aspects than game-based learning [3]. The concept of gamification enhances student's motivation and engagement is not short-term as compared to gamebased activities. Game thinking and game mechanics are becoming popular day by day. It is being observed that the trend of adoption of gamification is going in a very promising manner [25]. Game mechanics and game dynamics create engaging experiences and act as important tools of gamification [22]. The game mechanics include challenges, competition, feedback, rewards (redemption of points), whereas the dynamics include constraints, progression, implementation, and day-to-day analysis. To create a highly engaged gamified framework, the usage of game mechanics and dynamics should be practiced carefully [26]. Deployment of gamification in the education system results in rigid game mechanics. Motivation, commitment, and good behavior from students are the generic expected outcomes from students. The use of game elements in a nongame environment is increasing so that everyone can acquire appropriate skills and knowledge [27]. Gamification carries the use of game mechanics for engagement. Gamification-based solutions may fail if they lack a clear and formal design process [28]. Before deploying gamification in any field, it is important to know about the methods or frameworks that exist so that process of gamification design must be developed for a successful engagement experience. Games are an addictive part of people's daily life and gamification is encouraging the users to enhance their problem-solving capabilities with fun and learning mechanisms [29]. After exploring and completing the deployment process, it has been identified that usage of game mechanics and game design has shown a significant impact in the area of teaching software development processes [25]. Gamification may be used as a motivational and instructional tool to be embedded in the curriculum of computer science students. Redesigning of software engineering curriculum has been proposed and progression gamification techniques have been deployed during implementation [12]. The
Gamified learning activities are discussed to enhance student motivation and engagement. The activity is based on doing a pretest, reaching to the initial level, updating on leader board, learning the material, doing exercise, passing the minimum score, revising, and then proceeding to the next module [30]. The comparative analysis of the related existing system is described in Table 1.

2.2. Machine Learning in Education. Revolutionary change in the information and communication technology (ICT) has brought significant change in the teaching and learning process of the education system. One of the biggest sources of information nowadays is online tutorials, which is considered as one of the beneficial aspects to enhance student learning and performance. As there is a huge source of data availability, the researchers have applied the machine learning vector algorithm to identify and classify the best subject-related videos of a particular topic [32]. Nowadays data associated with real-world problems have many concerns related to inconsistency and inadequate data; fuzzy sets provide the solution to overcome this issue [33]. The major challenges involved in learning analytics include big data framework, data collection, privacy, security, and the selection of the optimal algorithm.

In terms of choosing the right machine learning algorithm, we have several dominant algorithms but choosing the best for a particular analysis is a tedious task [34]. Due to digital data availability, there is an increment in the development of various learning analytical techniques. Machine learning (ML) is a powerful technology that categorizes the data into a set of predefined generic classes. Supervised machine learning is applied on large-scale unstructured data of facebook groups, and $\mathrm{Ml}$ algorithms are used in text categorization to achieve a high rate of effectiveness. The research in this clearly shows that ML can be used as an effective method to identify who needs support within the personal environment of learning with the availability of educational data [35]. The problems related to decision-making are uncertain and fuzzy various algorithms, like CNS, ANFIS, are studied 'to cope up with complicated inconsistencies among data [36,37].

\section{Methodology}

Effective student learning is directly proportional to student classroom engagement. The classroom engagement can be enhanced by increasing the involvement of the students by providing a platform with the most considerable parameters such as the facility of asking questions inside or outside the classroom, the advantage of creative learning, and a sense of belonging among students. The primary goal for the gamified framework is an effective environment that helps to enhance the engagement of the students. On the other hand, the secondary goal is to create interesting learning solutions to enhance student engagement through progressive methods. A perfect trade-off between engagement and progressive loops would be the "Success Mantra." The transparency has been maintained in the proposed gamified 
TABLE 1: Comparative analysis.

\begin{tabular}{|c|c|c|c|c|c|c|c|c|c|c|}
\hline Sr.no & References & I1 & $\mathrm{I} 2$ & I3 & I4 & I5 & I6 & I7 & I8 & I9 \\
\hline 1. & Law et al. [22] & Yes & Yes & Yes & Yes & No & Yes & No & No & No \\
\hline 2. & Liu and Peng [23] & Yes & Yes & Yes & Yes & No & No & No & No & No \\
\hline 3. & Marques and Nixon [21] & Yes & Yes & Yes & Yes & No & Yes & No & No & Yes \\
\hline 4. & Akpolat and Slany [25] & Yes & No & Yes & Yes & 50 & No & Yes & Yes & No \\
\hline 5. & Uskov and Sekar [12] & Yes & Yes & Yes & Yes & 30 & No & No & Yes & Yes \\
\hline 6. & Cahyani [30] & Progression loop is not defined & No & Yes & Yes & 30 & Yes & No & Yes & No \\
\hline 7. & Mohamad et al. [31] & Progression levels are not mentioned & Yes & Yes & Yes & No & Yes & Yes & No & No \\
\hline
\end{tabular}

Engagement/progression loop = I1, game-based learning = I2, gamified learning = I3, game elements $/$ mechanics = I4, sample size = I5, gamified platform = I6, visualization of result $=I 7$, analysis/validation of results $=I 8$, continuous defined reward system $=I 9$.

framework to motivate the students for active participation in the various activities and inculcates high engagement in a student-centric environment. The gamified classroom learning leads to intrinsic motivation among students, funbased learning, opportunity to explore outside the classroom, and, most importantly, a visualization of their performance. Furthermore, the process of reengineering has been done by utilizing the decision-making efficiency of Machine Learning (ML). Every step of the proposed solution is explained ahead.

3.1. Prelude. Classroom learning is a complete package of content, pedagogy, delivery, and the assessment that helps to increase the student's engagement in the class. However, student engagement is only possible with the presence of the student in the classroom (student participation $=$ attendance) as visualized in Figure 2.

Classroom learning is dependent on the methodology adopted by the instructor that helps the student to involve in the learning process. In the era of the Internet, the latest technologies are emerging very rapidly around the world, it is the concerned instructors who can bring the change by using the latest pedagogies eliciting a keen interest from students in the class [38]; this would directly increase the overall class engagement. The contextual factors influence the implementation of gamification that involves the instructor's skill, design elements, background knowledge of participants, and the use of the latest gamified concepts [39].

Completing the task by fun learning is significantly better than completing the task by enforced learning. Effective pedagogical tools [40] must comprise healthy interactivity sessions and the use of 3-D video lectures. Furthermore, focus is on practical concepts rather than theoretical concepts, and tutoring is significantly done by the instructor for a compound set of environments to make a session preeminent in every aspect.

3.2. Context of the Study. The designed gamified framework is not specific to any course or any particular scheme. It is designed in such a manner that it can be incorporated with a different set of students belonging to diverse institutes. The gamified framework is being tested on more than 100 students on 6 different courses like oops, android, PHP, networking, data structures, and web designing, involving 2 different institute/college/university students of the Doaba region, Jalandhar. The teaching team comprises 10 faculties and each college/institute/university has one administrator to keep track of faculty implementing the successful gamified learning patterns. Informal consent has been taken from the faculty as well as students to witness the gamified framework. In the present scenario, we are following the teaching methods that include PowerPoint presentation lectures, seminars, group discussions in alternative weeks, if possible. Well-documented lesson plans, assignments, and evaluation criteria are enforced on students that lead to low engagement and lack of interest in the classroom. The design process of gamification involves the evolution of gameful systems that leads to complex interactions between the elements defined [1].

3.3. Procedure. This section provides detailed information related to the process of acquiring rewards-oriented coins and badges that help to enhance the motivation of the students toward learning. The proposed gamified framework is designed by adding new elements in education such as coins, badges, leader boards, and reward systems. All these elements can be gained by students with the help of a virtual coin-based attendance system, coin-based classroom discussion, flipped classroom challenge, game-based learning activities, online quizzes, organizing a class or group activities. The complete process is demonstrated in Figure 3 defining the flow of the gamified framework.

3.3.1. Virtual Coin-Based Attendance System. In the current education system, attendance is considered as one of the most imperative policy variables that define the scale of attention of the students toward their studies. The students with regular attendance are considered better performers. The increase in student regularity in the classes will enhance student classroom learning. In this gamified framework, the coins are associated with the attendance variable. Each student will be credited with virtual ATT coins (40 lectures $=4000$ ATT coins).

There exist 3 situations; either the student is present, absent, or not attending the class as he/she is involved in extra curricular activity assigned by the faculty that can be termed as duty leave. If a student is absent in the class, 100 ATT coins are subtracted from the total acquired coins, for e.g., $4000-100=3900$. A total of 100 coins per lecture are credited in the accounts of those students who are on duty 


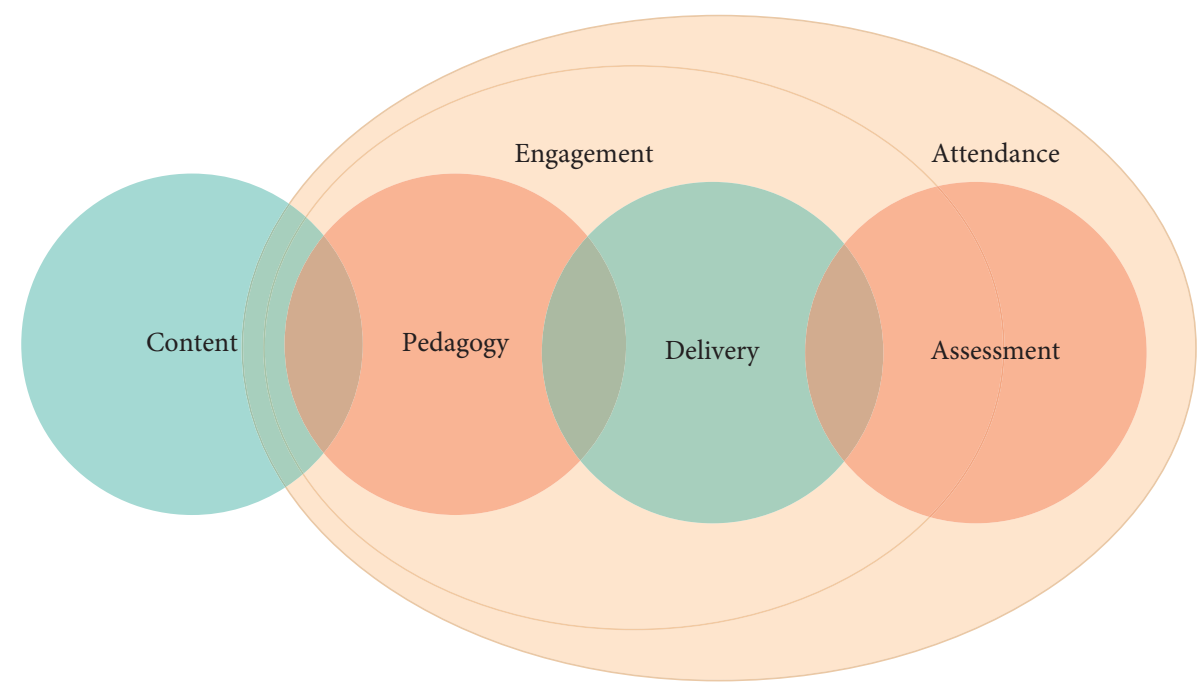

FIGURE 2: Aspects of classroom learning.

leave. Duty leave is leave assigned to students for participating in extracurricular activities. If a student is present in the class, ATT coins remain the same, that is, 4000 coins. The process of attendance-based coin distribution is explained in Algorithm 1.

3.3.2. Coin-Based Classroom Discussion. The faculty should encourage classroom discussion that allows speaking. Several doubts can be clarified and a quick revision can take place. This kind of environment leads to interactive teaching and engage students to think and explore the concepts that enhance speaking skills. The oral discussions or verbal questions asked during the lecture are not associated with any marks. Students evade answering or show insouciance to the classroom discussions.

To enhance student engagement, each student who is more involved and has active participation will be awarded virtual coins, and badges will be assigned weekly. Each faculty will have 100 ATT coins per lecture. The faculty has to allocate coins to students by asking verbal questions related to previous classes or current topics taught in the classroom. Each question asked by faculty during the lecture will be of 10 ATT coins, and if the student answered correctly, 10 coins were assigned which are clearly explained in Algorithm 2. If the answer given by the student is incorrect, no coins will be deducted as a gamified framework promotes positive mechanics.

3.3.3. Student challenge. In a gamified framework not only faculty have the option to ask questions to students. Even students can ask questions to fellow students related to the topics discussed in the classroom. The question will be verified by the faculty and the virtual coins will be awarded to a student for giving a challenge to his/her fellow friends. The student who will answer within the least login time will be awarded bonus coins. In classroom learning, we have observed that the students are scared of asking questions to faculty. Therefore, in this gamified framework, a student can ask a doubt or questions through the application at any point in time and the complete process is explained in Algorithm 3.

3.3.4. Weekly Online Quiz. The weekly online quiz can help the faculty to check the level of understanding of the concept taught during the sessions. The quiz will be point-based and multiple options will be given to students. The top 5\% of students who will have the maximum correct answers in the minimum period will be assigned double ATT coins and the rest of the students will be assigned ATT coins based on the correctly answered questions. The process of online quiz performance-based coin distribution is explained in Algorithm 4.

3.3.5. Organizing Class Events/Participating in Extracurricular Activities. This would be one of the richest tiers in which the student can gain a lot of virtual coins according to the event or task planned by the students. If the student participates in international conferences or international events, 500 ATT coins will be assigned. Any national event participation will fetch 300 ATT coins, interuniversity participation will gain 200 ATT coins, and participation or organizing college or class events will gain 100 ATT coins. Student participation in extracurricular activities is very important, but it has been observed that they resist projecting their talent due to loss of attendance or due to pressure of studies. Students involved in innovations like developing a research-based application and improving the existing algorithms, for example, involving concept of image processing that synthesizes the [41] novel images in combination with two images, will be highly appreciablex and will be awarded.

3.3.6. Flipped Classroom. In classroom learning, more focus is given to the completion of the curriculum. The teacher's focus is on explaining the concept without any participation of 


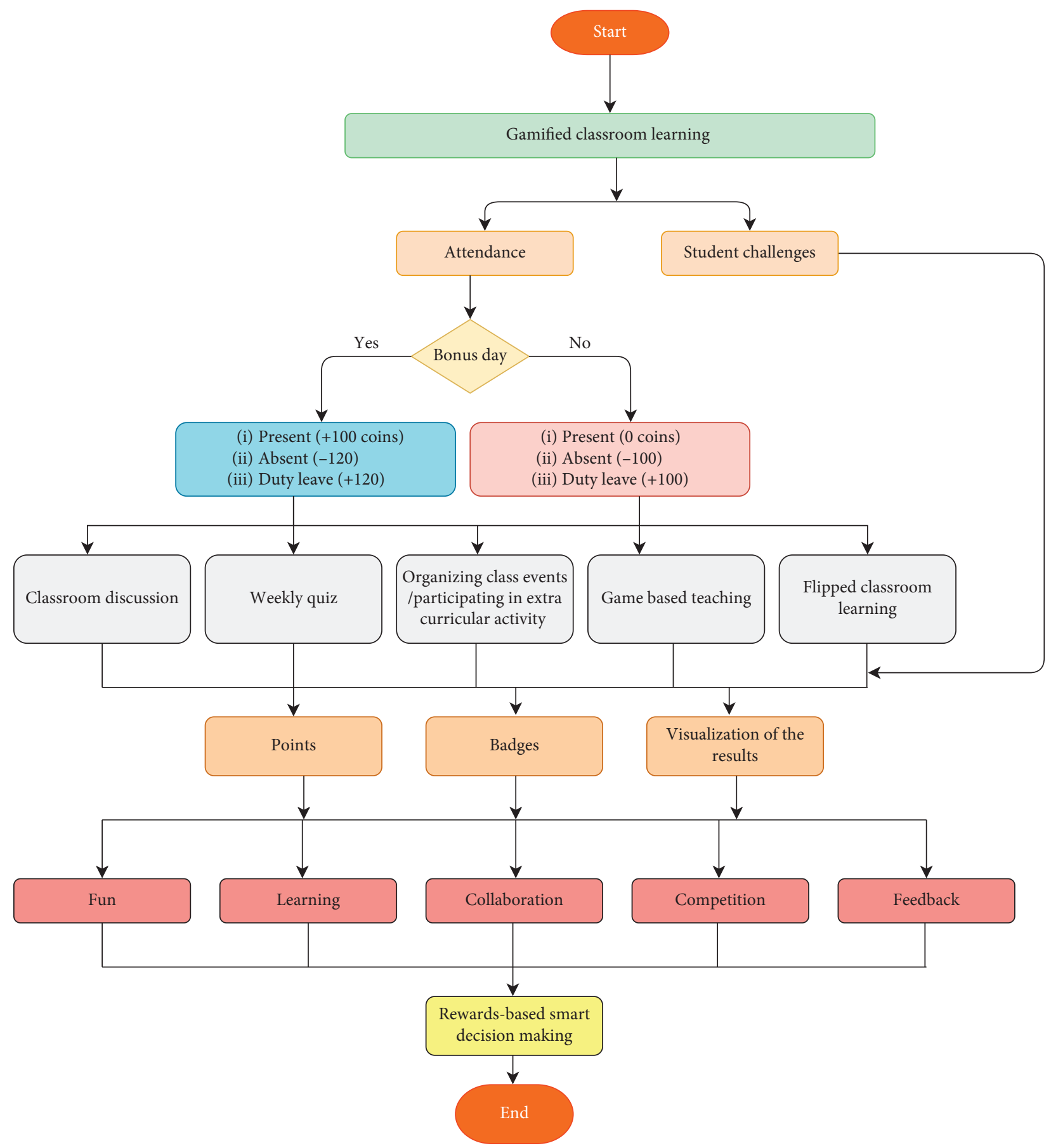

Figure 3: Flow chart of gamified classroom learning.

students. In contrast, a weekly one-day concept of the flipped classroom will be implemented that incorporates independent prework through self or online learning. The complete session of the flipped classroom will be based on student active interaction and valuable discussions that can help the students to achieve knowledge beyond the books. The top-performing students will be assigned with star performer badges.

3.3.7. Use of Game-Based Methods. To make the session more interesting, fun-oriented game-based learning methods should be used. The major differences between game and gamification points are elaborated in Figure 4. Game-based learning can be part of the gamified framework used to enhance the education system. Motivation is considered as a convincing medium to involve people for their active participation in game playing. It has been identified that games engage students in a promising manner as compared to other mediums. They have also concluded that computer games are a significant part of a youngster's life. Any game designed for learning purposes must have learning dynamics as well [42]. The traditional 


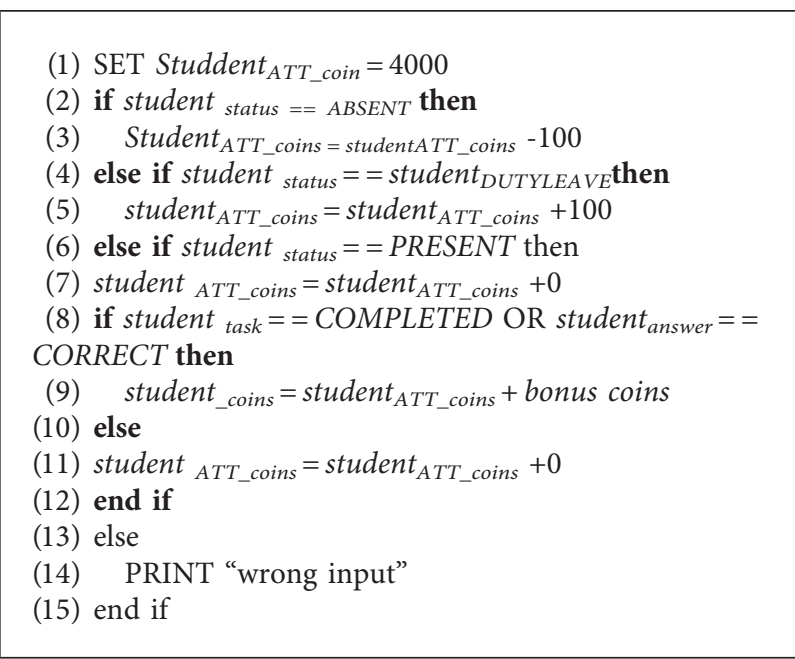

Algorithm 1: Attendance-based coin distribution.
(1) Input: student $t_{A T T \_c o i n s}$, question
(2) if question $==$ correct then
(3) student $_{A T T_{-} \text {coins }}=$ student $_{A T T_{\_} \text {coins }}+10$
(4) else
(5) student $_{A T T \text { coins }}=$ student $_{A T T_{-} \text {coins }}$
(6) end if

Algorithm 2: Classroom discussion coin.

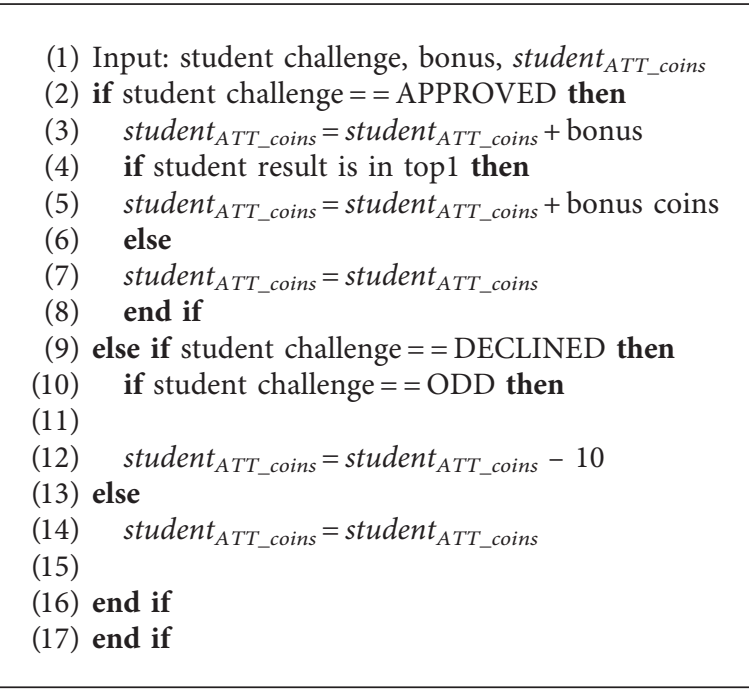

Algorithm 3: Student involvement-based coin distribution.

education system follows learning by knowing approach. As technology is commanding, one should adopt the skills of learning by doing also. The traditional education system can be made practicable with the help of pedagogical elements such as tasks and levels. The games such as flashcard, chain reaction, and out of box thinking can be incorporated into regular teaching to enhance student engagement. Games are part of the gamification process to enhance user engagement, productivity to achieve the desired results. Game-based learning provides comprehensive learning with a sense of authentic circumstances giving a chance to expand one's aspects of science. As an operative training approach game-based learning facilitates students with captivating participation. Games 
(1) Input: student $t_{A T T_{-} \text {coins }}$, bonus

(2) Read student list S List

(3) for student in S List do

(4) if student is in top 5 then

(5) student $t_{A T T \_c o i n s}=s_{\text {student }}$ ATT_coins $_{\text {correct_ans }} \times$ bonus $\times 2$

(6) else

(7) studentATT coins $=$ studentAT $T$ coins + correct ans $\times$ bonus

(8) end if

(9) end for

Algorithm 4: Online quiz performance-based coin distribution.
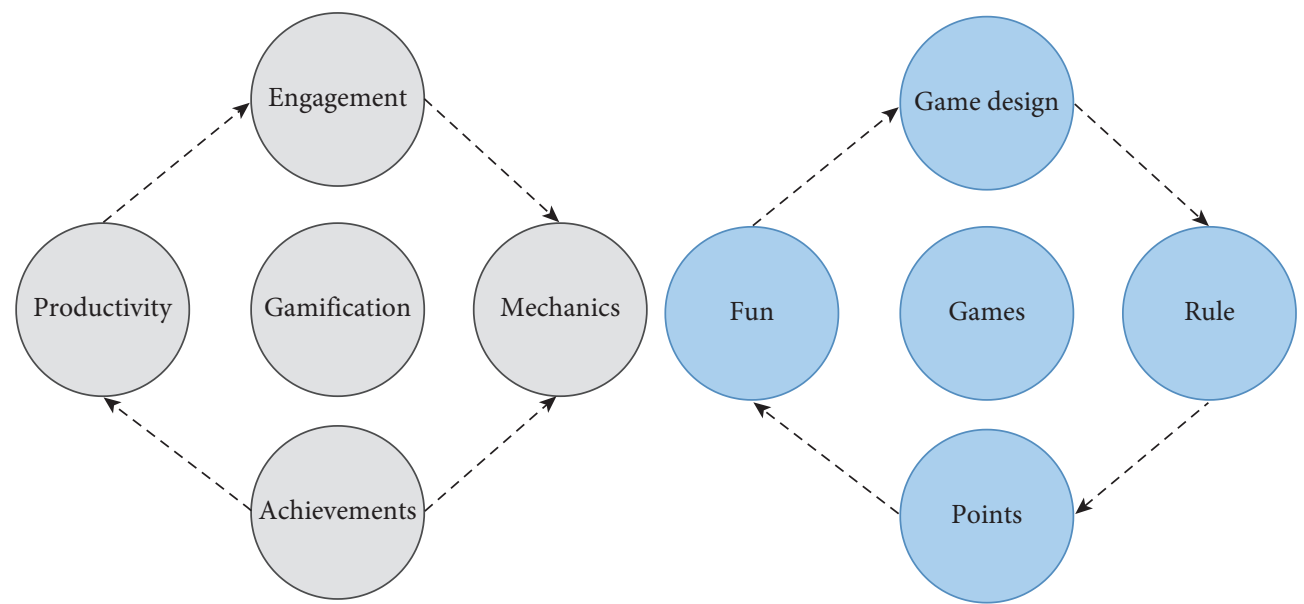

FIGURE 4: Difference between game and gamification.

include fun, attractive game designs, rules, and short-term engagement.

Games have well-defined rules, levels, and possibility of losing whereas gamification intrinsically rewards the player to enhance motivation.

3.3.8. Visualizing Real-Time Analysis. Real-time analysis can be done to check student engagement with the number of virtual coins earned by the student based on attendance, knowledge, and active participation. The number of virtual coins gained or lost can be viewed by the faculty as well as admin to keep a proper track of students' performance as depicted in Figure 5.

3.4. Describing Players. The description of players in Amy Jo Kim's model. Students and faculty will be active players. According to Amy Jo Kim's 1 model, Figure 6 explores the model of gamified classroom learning.

3.5. Device Activity Loops. For gamified learning, we need to focus on two major aspects, namely, engagement and progression.

3.5.1. Engagement Loop. It delineates the pathway that motivates the individual to do a particular task persistently.
It keeps the process moving. ATT-coins-based attendance system, coin-based classroom discussions, and weekly quizzes are part of the engagement loop.

3.5.2. Progression Loop. The concept of randomness will be involved in the attendance module; on a particular day generated by the system, the students will get bonus ATT coins for attending the particular lecture and will be credited as per Algorithm 5. Similarly, the student who is absent on a particular day will lose ATT coins. Bonus day is different from normal attendance days as the student will gain coins for being present in the class. On the bonus day, If $r=10$, then those present will gain 110 ATT coins, those absent will lose 120 ATT coins, and those on duty leave will gain 120 ATT coins.

Game-based teaching activities, flipped classroom learning, participating in extracurricular activities, and providing a challenge to students make the teaching more effective and collaborative.

3.6. Deployment of Tools. These are the virtual elements that are used to create a gamified environment and enhance the enticement factors. Game elements describe not only the control means to gamify various actions but also several activities, habits in a combination to design a persuasive and participative user experience. 


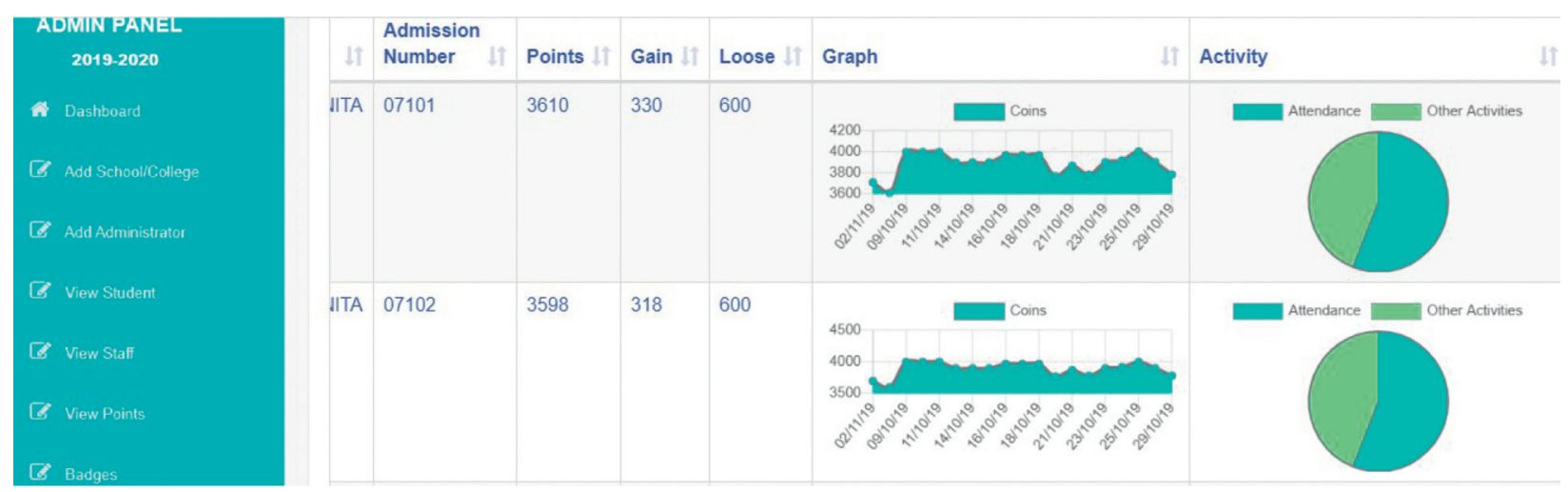

FIGURE 5: Visualization of student's overall performance.

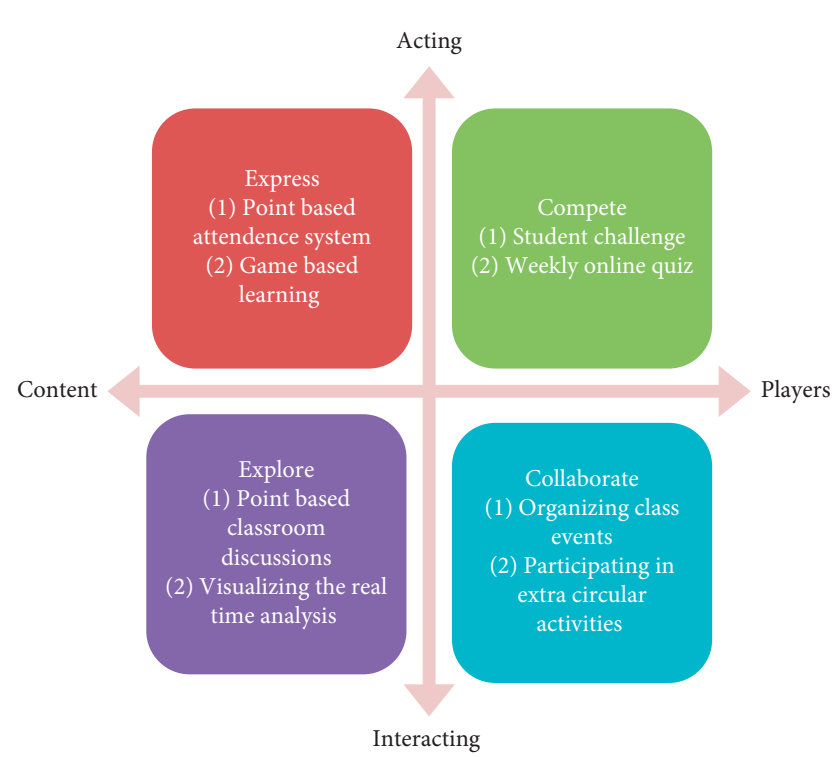

Figure 6: Amy Jo Kim's model for gamified classroom learning.

3.6.1. Points/Coins. Points/virtual coins will be earned through classroom discussion, quiz, student challenge, attending regular lectures, and organizing events. Coins allocated to students motivate them to perform better.

3.6.2. Badges. The star performers will be awarded weekly badges that can be shared on social media. They are virtual symbols mentioned in Figure 7 that will be assigned to students for their various achievements.

3.6.3. Leader Boards. The names of the top scorers will be displayed; this would create zeal of competition, and students will be rewarded with tangible and intangible reward mechanism. Topper's IDs are displayed on the leader board during the implementation as mentioned in Figure 8.

3.6.4. Analytical Graphs. This would depict one's progress of gaining coins through attendance, quizzes, organizing events, and classroom discussions, as mentioned in Figure 5. When students win badges, points, and their names are displayed on leader boards depicting students' classroom performance, it makes gamification a long-term concept in contrast to focal game activities that exist for a short span of time [3].

3.6.5. Rewards. The student who has more than the initial credited ATT COINS for the particular course code can redeem those coins. Rule: for redemption, coins for a particular course should be $>$ initial ATT coins of the course (e.g. > 4000). Rewards can be tangible or intangible according to the faculty and the institution's consent. Rewards are divided into three tiers.

Tier 1 consists of rewards that will be awarded to students who gained maximum coins through attendance

Tier 2 rewards will be availed by students who gained maximum coins through the quiz

Tier 3 rewards will be availed by students who gained maximum points through extracurricular activities

Rewards can be assigned to students on a weekly or monthly basis according to the decision of the institution administrator. Various decision-making mechanisms can be incorporated for assigning rewards. There exists a complete barter system wherein students earn virtual ATT coins and can redeem their earrings in various tiers, as described in Figure 9.

3.7. Reengineering of Reward-Based Decision-Making. The interactive decision is a module in the proposed model that helps the student to provide maximum permutation combinations concerning the badges earned through one of the most inspiring decision algorithms of the machine. For interactive decision-making, adaptive neuro fuzzy inference system (ANFIS) model is used to calculate the maximum combination of earned coins as presented in Figure 10 [43]. The coding of the ANFIS method is done using the PYTHON software. The model is trained and the concept of backtracking algorithm is used for optimizing the weights of the model. Table 2 explained the range of selected parameters that are used to provide the input to the ANFIS model for decision-making. 


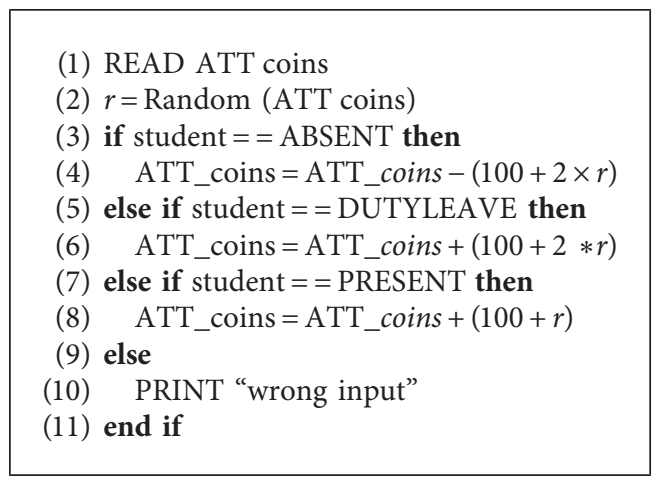

Algorithm 5: Bonus attendance-based coin distribution.

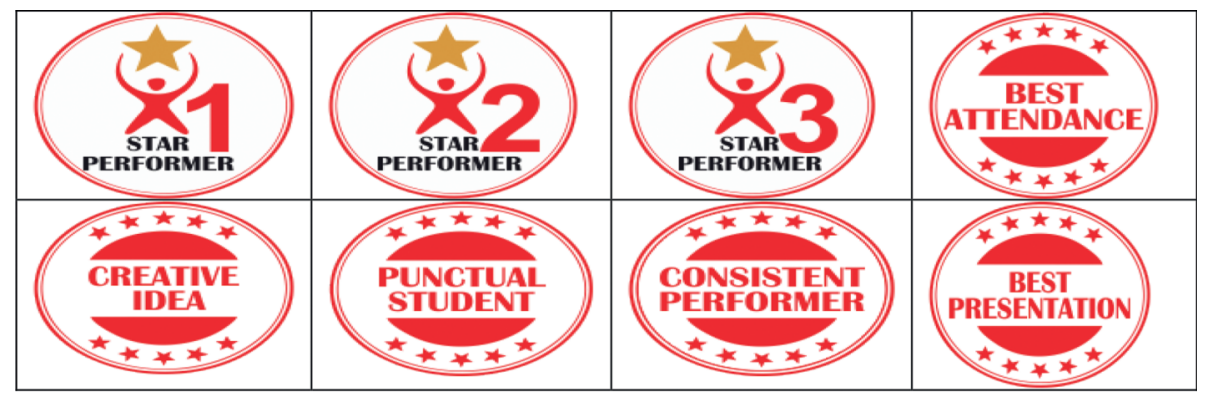

FIGURE 7: Badges designed for gamified classroom learning.

\begin{tabular}{ccc}
\multicolumn{3}{c}{ Top 5 students } \\
\hline$\#$ & Student id & Coins \\
\hline 1 & O7services_1632647 & 5545 \\
2 & O7services_1904 & 5510 \\
3 & O7services_17245828 & 5242 \\
4 & O7services_1724525 & 5230 \\
5 & O7services_1704216 & 5229 \\
\hline
\end{tabular}

FIGURE 8: Topper's registration numbers on the leader board.

The first step of the model involves input variables that are parental, i.e., coins gained through attendance and coins gained through other activities that involve quiz, classroom discussion, challenges, etc., for the prediction of rewards. The influential parameters are selected and listed:

(i) Member function output: linear

(ii) Type of member function: Gaussian

(iii) The method used for optimization: hybrid

(iv) Increase the rate of step six

3.7.1. Layer 1 (Fuzzification). Adaptive nodes in the ANFIS architecture are denoted with square boxes. There is the existence of node I of the first layer that takes values as inputs in the form of labels that are linguistic, such as Low,
Moderate, and High. The $(X)$ helps to regulate the level of input and also signifies the node function. For instance

$$
\begin{aligned}
o_{k}^{1} & =\mu A_{i}(\text { attendence }) \forall i=\left\{A_{1}=\text { low, } A_{2}\right. \\
& \left.=\text { moderate, } A_{3}=\text { high }\right\}, \\
o_{k}^{1} & =\mu B_{i} \text { (other activities) } \forall i=\left\{A_{1}=\text { low, } A_{2}\right. \\
& \left.=\text { moderate, } A_{3}=\text { high }\right\} .
\end{aligned}
$$

3.7.2. Layer 2 (Product). The next layer of the network signified as the second layer consists of fixed, rule-based nodes. This layer is denoted by and is also known as the membership layer. The firing strength is known by each node's output wi that is marked as a rule. The following equations indicate that the firing strength is calculated by utilizing the product rule.

$$
\begin{aligned}
O_{k}^{2} & =\mu A_{i}(\text { attendance }) c r \\
\mu A_{i} \forall i & =\left\{A_{1}, A_{2}, A_{3}\right\}=3, \\
\mu B_{i} \forall i & =\left\{A_{1}, A_{2}, A_{3}\right\}=3 .
\end{aligned}
$$

3.7.3. Layer 3 (Normalization). The fixed nodes are defined in the third layer of the network. The firing strength ratio of $i_{\text {th }}$ rule is calculated through this rule. The following equation helps to perform firing strength normalization. 
The barter system

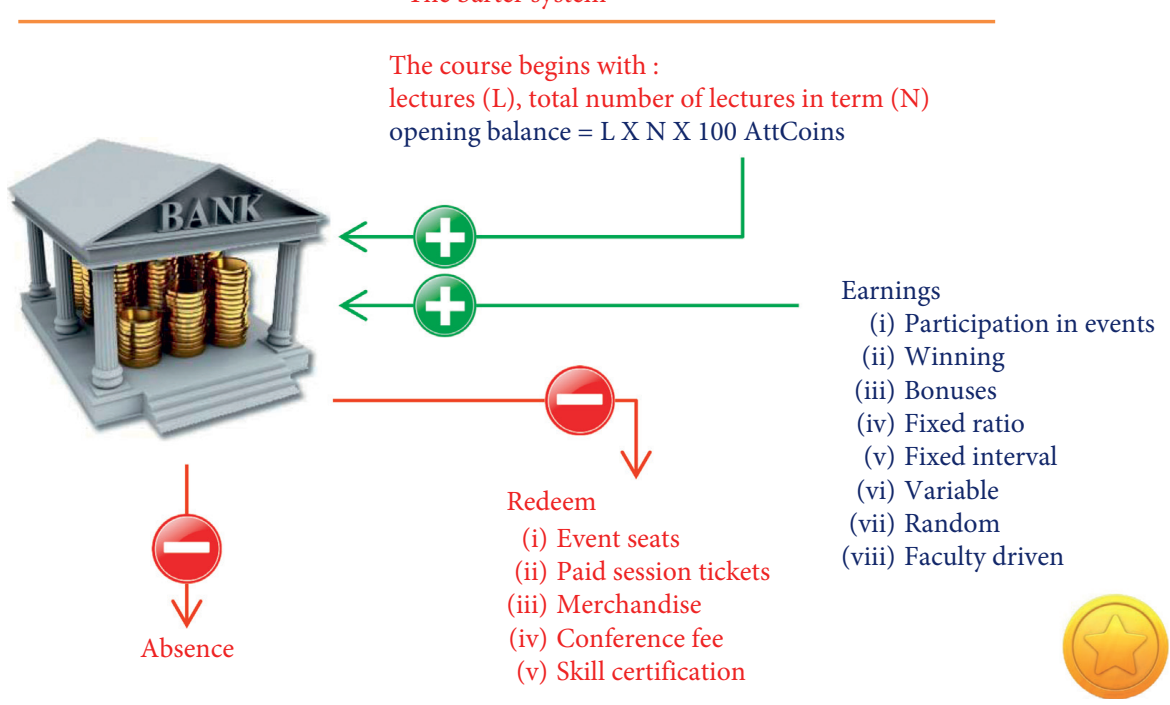

Figure 9: Barter system.

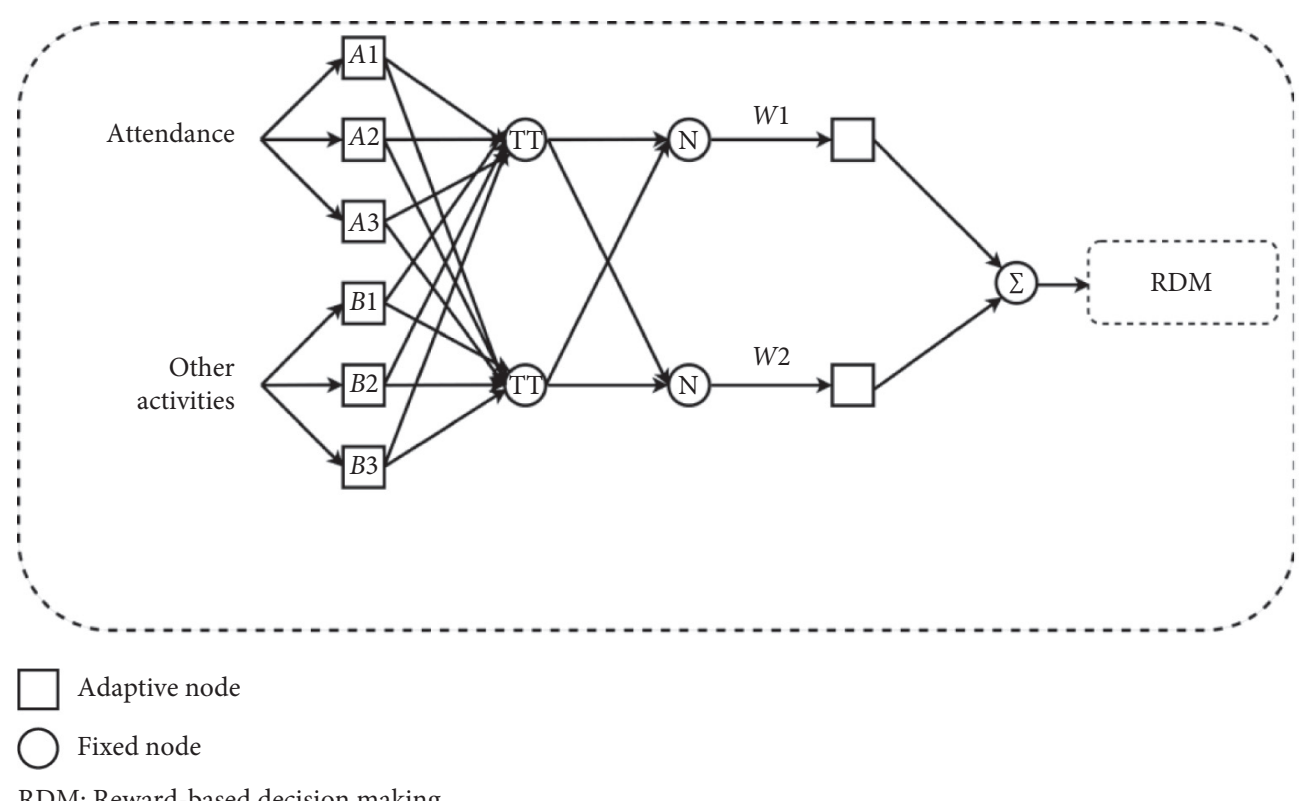

FIgURE 10: ANFIS-based smart decision-making.

TABle 2: Predescribed range of selected parameter.

\begin{tabular}{lcc}
\hline Sr. no. & Range & Decisive factor \\
\hline 1. & $<50$ & Low \\
2. & $50-120$ & Moderate \\
3. & $>120$ & High \\
\hline
\end{tabular}




$$
O_{K}^{3}=\frac{W_{i}}{W_{1}+W_{2}+W_{3} \ldots \ldots \ldots \ldots \ldots \ldots+W_{n}}=\overline{\mathrm{W}} .
$$

3.7.4. Layer 4 (Defuzzification). The fourth layer known as defuzzification executes the task by using the concept of multiplying fuzzy function with the output of previous nodes. By the following node functions, each node can be adjusted.

$$
\mathrm{O}_{k}^{4}=\bar{W}_{i} * f_{i}=W_{i}\left(a_{i} \mathrm{x}+b_{i} \mathrm{y}+\ldots \ldots .+r_{i}\right)
$$

3.7.5. Layer 5 (Output). The ultimate composite probability is calculated through the 5th layer, which is used to calculate the scale of susceptibility. The actual output is determined by considering all outputs of pervious nodes of layer 4 defuzzification and then applying weighted average summation operation.

$$
\mathrm{O}_{k}^{5}=\sum_{k} \overline{W_{i}} * f_{i}=\frac{\sum_{k} W_{i} * f_{i}}{\sum_{k} W_{i}} .
$$

\section{Implementation}

To extend the use of gamified framework beyond the existing contexts, there is a need for systematic study keeping in mind the effects of different individuals and situational contexts [1]. The effect of gamified learning was analyzed with the help of the following four products.

\section{Gamified learning management system \\ Gamified learning application \\ Game-based application (Geeker's hub) \\ Interactive reward-based decision-making}

4.1. Gamified Learning Management System. It is a repository used to store and track the information on a timely basis. The gamified learning management system is divided into three main panels that include admin, school coordinator, and faculty. Admin creates an account for the school coordinator and the school coordinator assign students to a particular faculty. All the tasks performed by the faculty like registering students, assigning online ATT coins based on attendance, assigning classroom discussion coins, preparing online quiz, assigning badges, visualization of results is done through the designed platform.

4.2. Gamified Learning Application. It is a mobile-based application that is used by students to perform online quizzes, track the online coins gained daily, and redeem coins in the form of rewards.

4.3. Game-Based Application (Geeker's Hub). Various games are incorporated in this application, which includes an online housie game used to test student's aptitude knowledge. Another game is designed in the form of flashcards to judge students' knowledge of the $c$ language. Games act as an intrinsic motivational factor for students.

Each product developed has a novel structure and consists of unique features, as mentioned in Figure 11. The use of new technologies like the Internet, mobile phones, and online activities has made a huge difference in the education system as well [44]. Implementation of the latest information systems makes an impact on individual learning and increases the motivation and engagement of students. The concept of gamification is trending [45] because of its relatable elements that include fun-based learning, performing the task step by step, and challenges defined in a progressive manner.

The quintessence of gamification does not only focus on technology, its diversity includes a better learning environment that increases student motivation and engagement by involving the reward system [46]. The gamified learning pattern is designed in such a manner that it does not completely sideline the traditional learning techniques followed in the education system. Traditional education is enhanced by adding virtual ATT coins, badges, rewards, funbased learning, and game-based activities to have higher engagement among the students.

\section{Results and Discussion}

In the field of gamification, the concept of high psychological ability are involved that demonstrate dimensions of the individuals, design elements, and qualities that affect user engagement and experience. The concept of gamification is not only about assigning coins to students, but it should also involve student creativity, collaborative activities, gaming strategies, and creating a situation for the overall involvement of students [26]. Considering all the above points mentioned, the attendance-based gamified framework was implemented in two different institutes or universities. There should be a careful integration of the gamified learning context [20]. The proposed framework is designed in such a manner that it is not specific to any particular course or university.

5.1. Student Engagement and Regularity Analysis. It was implemented in an institute where there was no attendance compulsion for the students. With the help of a gamified framework, students were intrinsically motivated to attend the classes that included a coin-based attendance system, fun-based learning, online quiz, and verbal discussion. Enhancement in attendance can be examined in all six sections, as presented in Figure 12.

For university students, $75 \%$ attendance was mandatory; however, change in the attendance is negligible as compared to previous months where the gamified framework was not applied. In the second class, it has been observed that there is a drop of 3\% attendance in gamified framework as compared to nongamified framework, as mentioned in Figure 13. It has been decided to perform further analysis in order to enhance the gamified framework in the future. 


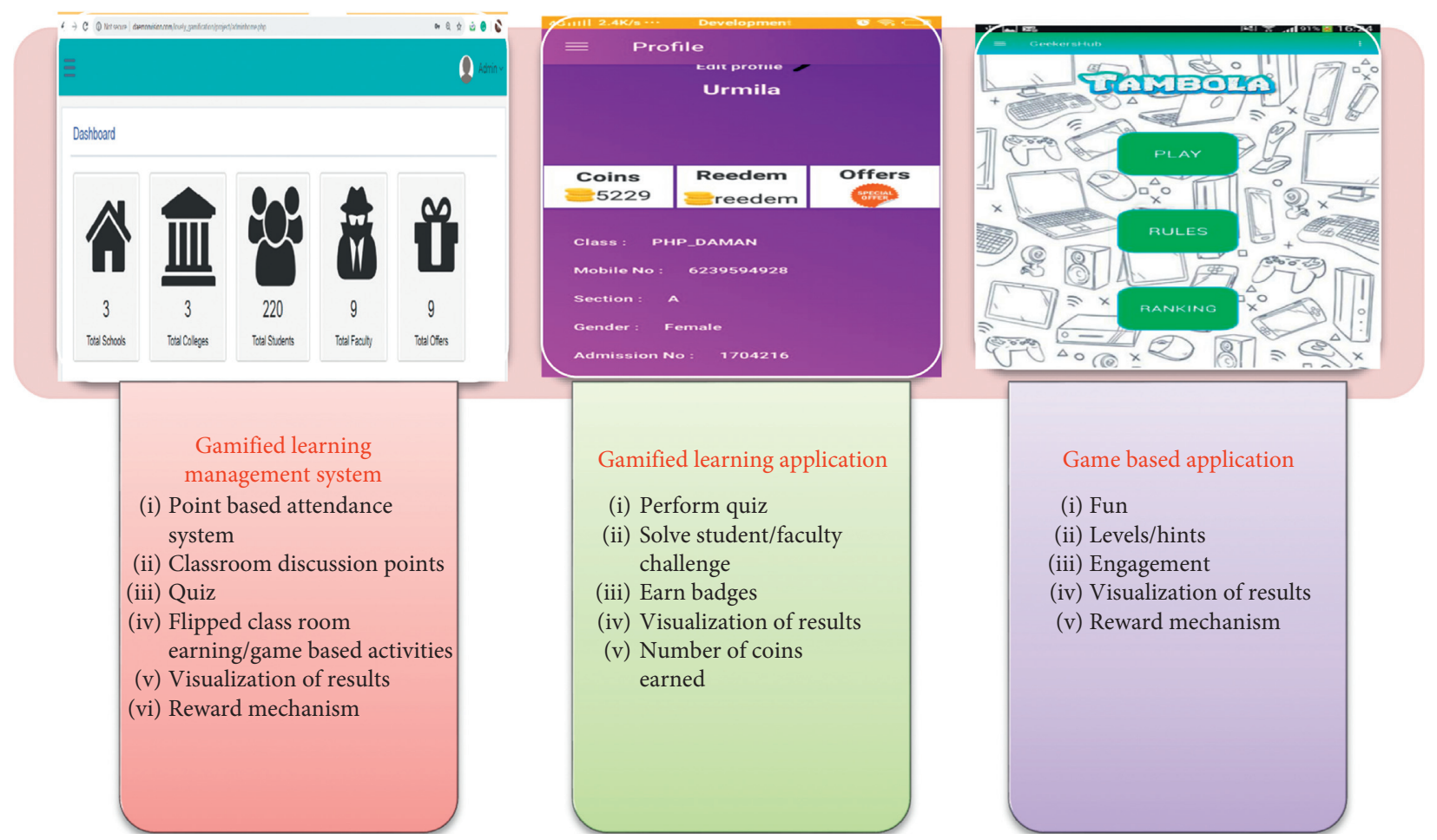

FIGURE 11: Features of the applications used for the implementation of the gamified framework.

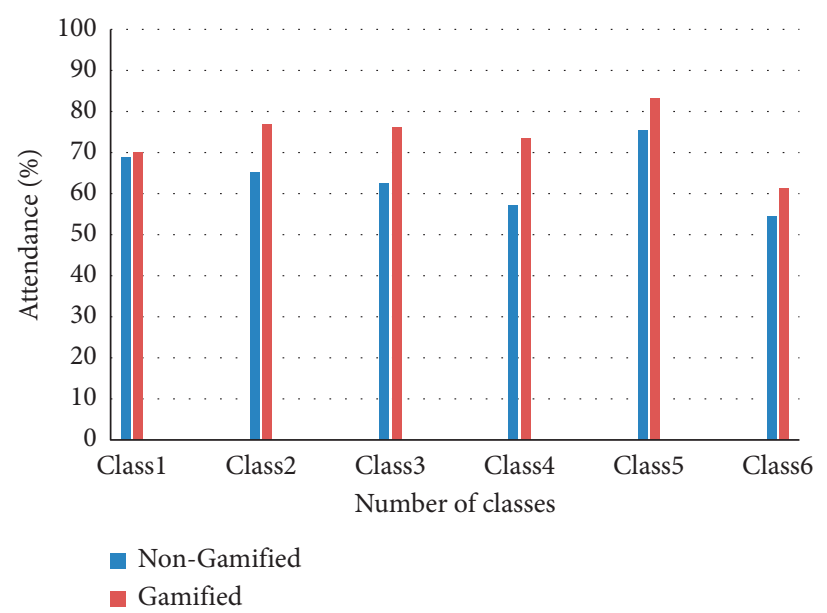

FIgURE 12: Attendance comparison of non-gamified vs gamified classroom learning.

5.2. Overall Performance of Students in the Gamified Framework. In scenario 1, students performed all the activities and game-based learning sessions with high motivation and enhanced game mechanics and dynamics involved by gaining more and more ATT coins in their weekly performance. There was a gradual increase in the weekly points gained, as illustrated in Figure 14, for continuous three weeks and a drop in points gained can be seen.
The calculated outcomes represent the enhancement in student engagement; however, more intrinsic learning methods can be incorporated.

The coins gained in Scenario 2 by the institute, students showed remarkable results in the first and second week of experimentation. However, a drop in points gained has been found in the third week, as demonstrated in Figure 15. Reasons were analyzed by the faculty members as it was a 


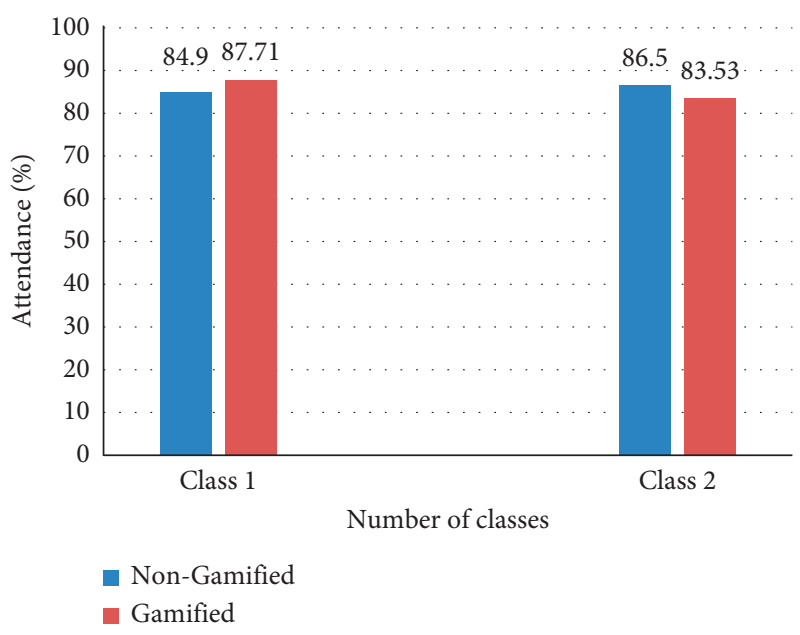

FIGURE 13: LPU attendance comparison of nongamified vs. gamified classroom learning.

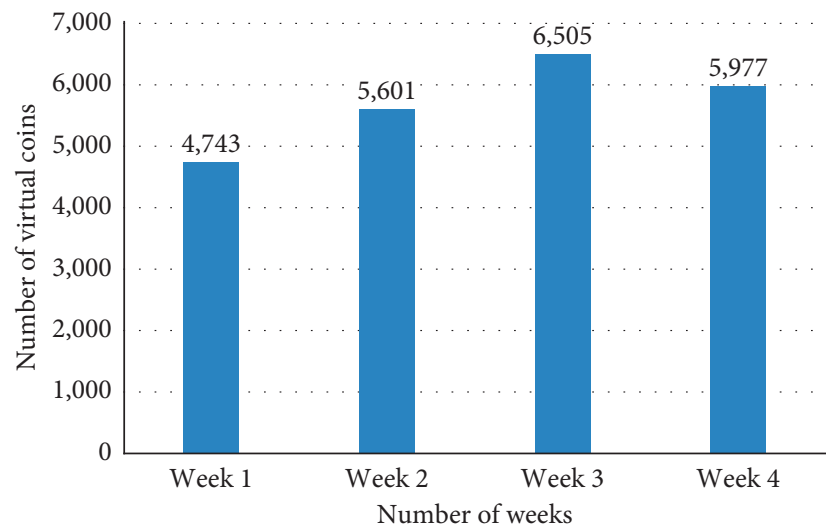

FIGURE 14: Scenario 1: weekly performance of students.

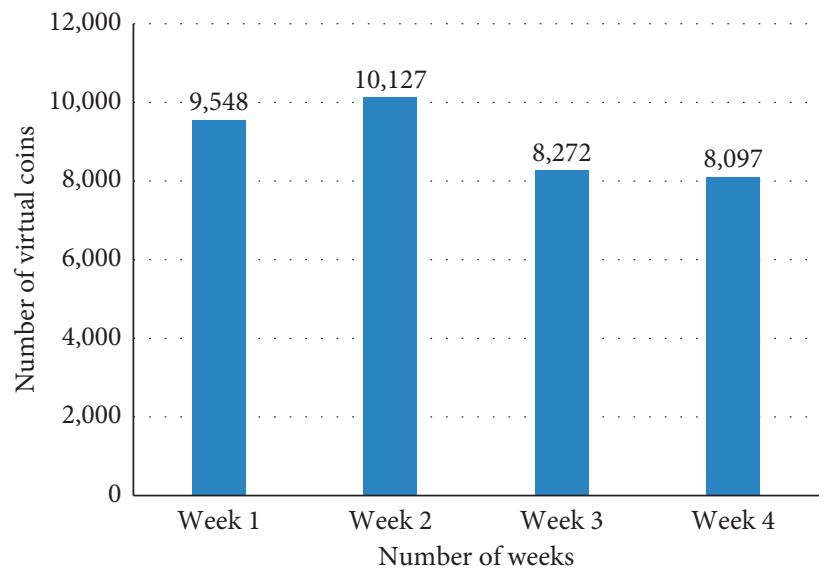

FIGURE 15: Scenario 2: weekly performance of students. 
TABLe 3: Examples of 9 fuzzy rules.

\begin{tabular}{lccc}
\hline Rule no. & Attendance & Other activities & Decision-making \\
\hline 1. & Low & Moderate & Decision $_{1}$ \\
2. & Moderate & Decision $_{2}$ & Decision $_{3}$ \\
3. & High & Moderate & Decision $_{4}$ \\
4. & Low & Low & Decision $_{5}$ \\
5. & Moderate & High & Decision $_{6}$ \\
6. & High & High & Decision $_{7}$ \\
7. & Low & High & Decision $_{8}$ \\
8. & Moderate & Low & Decision $_{9}$ \\
9. & Moderate & High & \\
\hline
\end{tabular}

TABLE 4: Training and testing performance.

\begin{tabular}{|c|c|c|c|c|c|c|}
\hline \multirow{2}{*}{ Performance parameters } & \multicolumn{2}{|c|}{ FS } & \multicolumn{2}{|c|}{ ANN } & \multicolumn{2}{|c|}{ ANFIS } \\
\hline & Train & Test & Train & Test & Train & Test \\
\hline Accuracy & $94.26 \%$ & $90.68 \%$ & $98.23 \%$ & $91.57 \%$ & $97.62 \%$ & $94.58 \%$ \\
\hline Sensitivity & $95.41 \%$ & $92.76 \%$ & $97.85 \%$ & $93.28 \%$ & $98.17 \%$ & $95.41 \%$ \\
\hline Specificity & $94.78 \%$ & $89.57 \%$ & $97.13 \%$ & $91.04 \%$ & $97.82 \%$ & $93.52 \%$ \\
\hline F-measure & $94.69 \%$ & $91.54 \%$ & $96.28 \%$ & $92.58 \%$ & $98.20 \%$ & $94.43 \%$ \\
\hline
\end{tabular}

festive week and India's most popular festival was held this week.

Faculty's perception 1: students experienced first-time, fun-based learning through games that enhanced students' creativity and classroom interaction.

Faculty's perception 2: students were highly motivated as they wanted to gain more attendance coins on a regular basis and performed the activities to the best of their capabilities.

The implementation of gamified framework and its successful implementation on mechanisms are designed as an open-ended method, irrespective of the course and the program being studied, and this framework has endeavored on multiple courses. A meaningful gamification course design has been introduced representing the examination of the relationship between a gamified course, learning process, student involvement, and progress. In addition, in each stage of the course, design process outcome indicators and engagement of students have been identified that offer meaningful gamification. By focusing on meaningful teaching and learning, the results conclude that the technology-mediated gamification can facilitate supplementary enhancements.

5.3. Point-Based Decision-Making Analysis. The attendance and other activities are considered as two parameters of the study which are used to evaluate the relationship of pointbased decision making. ANFIS contains the data processing efficiency of the two most consistent algorithms of machine learning, ANN and Fuzzy logic, for relationship analysis. Table 3 defines the inference system with nonlinear functions. A total of 9 Fuzzy rules are used to calculate the compounded relationship vector to evaluate every possible relationship for attendance and other activity-based events.
A total of 63 datasets are formed that contain more than 900 singular events. These singular events are related to attendance and other activities involved in the enhancement of student engagement. To fulfill the purpose of training and testing, 50 datasets are used for training, and the remaining 13 datasets are used to assess the performance of the system. The training and testing performance of the designated decision-making machine learning models are represented in Table 4. The various other performance assessment metrics are sensitivity, accuracy, specificity, and F-measure that are intended for performance determination. Analysis based on error rates, such as root mean square error, median absolute error, and $R^{2}$, are statistical measurements that are calculated to categorize the proposed solution performance.

The performance of the ANFIS model gives better results in comparison to FS and ANN after analyzing the results in Table 3. The comparative accuracy achieved by the ANFIS model for reward-based decision calculation is $94.85 \%$, whereas prediction accuracy with $\mathrm{ANN}$ is $91.77 \%$ and accuracy by FS is $90.86 \%$. The improvement in terms of specificity is $93.25 \%$ in comparison to predicted models, namely, ANN (91.14\%) and FS (89.76\%). The level of improvement showed by sensitivity and F-measure are the same. From the above-calculated values, it can be inferred that the ANFIS classifier is far more competent for complex and nonlinear problems along with the fact it is more sensitive for multifactor-based relationship analysis.

After the evaluation of Table 5, it has been observed that the distribution value is much closer in comparison to FSand ANN-based predictive outcomes. The value of $R^{2}$ signifies that results are much closer to the regression line by attaining an accuracy of 0.91 in comparison to the accuracy attained by ANN (0.85) and FS (0.83). In comparison to $\mathrm{VAF}, \mathrm{RMSE}$, and MEDAE parameters for error calculation, it is has been found that the present model produces low errors. We can conclude that the ANFIS model shows an 
TABLE 5: Summarized description of the best ANFIS models' statistical criteria and conditions.

\begin{tabular}{|c|c|c|c|c|c|c|}
\hline \multirow{2}{*}{ Error parameters } & \multicolumn{2}{|c|}{ FS } & \multicolumn{2}{|c|}{ ANN } & \multicolumn{2}{|c|}{ ANFIS } \\
\hline & Train & Test & Train & Test & Train & Test \\
\hline RMSE & $4.20 \%$ & $3.84 \%$ & $2.45 \%$ & $1.77 \%$ & $1.75 \%$ & $1.30 \%$ \\
\hline$R^{2}$ & $0.89 \%$ & $0.81 \%$ & $0.87 \%$ & $0.84 \%$ & $0.92 \%$ & $0.90 \%$ \\
\hline VAF (\%) & 90.17 & 81.65 & 87.66 & 79.69 & 93.68 & 88.89 \\
\hline MEDAE & 1.88 & 1.49 & 2.43 & 1.19 & 1.59 & 1.19 \\
\hline
\end{tabular}

acceptable error rate and has high selectivity and can be used for reward system mechanisms.

5.4. Predictor Stability Analysis. System stability is defined as a measure of occurrence, which is used to analyze stability analysis over a period. The evaluation of system stability takes place for a limited period concerning Absolute Average Shift (AAS). The statistical measure value of AAS lies between 0 and 1 . The value of 0 depicts good stability, whereas the value of 1 depicts the low performance of the system over a given period. As mentioned, the register minimal AAS value to the proposed model is 0.18 , AAS maximal value is 0.52 , and the average value of the overall experiment is 0.29 . The above results determine that the technique presented is quite stable to check the performance-oriented, real-time decision-making.

\section{Conclusion}

Student engagement has been considered as one of the major concerns in classroom learning. The purpose of implementing a gamified framework for higher education is to increase student engagement and diverse learning methods. It helps to provide the opportunity for students to explore several learning methods through various activities. The mechanics and dynamics, such as challenges, competition, rewards, progression, implementation, and day-to-day analysis, play an important role in achieving considerable results. Specifically, in this research (i) students' engagement and regularity to classes are examined through attendance in the gamified framework; (ii) the overall performance of students is evaluated in the gamified framework on a weekly basis; (iii) a microlevel study has been conducted that elaborates student participation concerning different attributes of gamified framework; (iv) machine-learning-assisted decision-making solution is proposed for reward distribution to enhance the engagement of students in the classroom. Activities, such as verbal maneuver and fun-based learning, define the high involvement of the faculty that leads to the implementation of a successful gamified framework. The proposed gamified framework is validated by performing a comparative analysis. The calculated outcomes represented the high involvement of the students in the gamified framework and gained ATT coins in huge amounts.

6.1. Future Scope. Replicability of the gamified framework at various levels of education, including different streams, higher education, and secondary education is an area of research. The usage of more intrinsic game elements with combinational usage of components, mechanics, and dynamics to target specific motivations of players is still challenging.

\section{Data Availability}

The dataset used to support the findings of this study are available from the corresponding author upon request.

\section{Conflicts of Interest}

The authors declare no conflicts of interest.

\section{References}

[1] L. E. Nacke and S. Deterding, "The maturing of gamification research," Computers in Human Behavior, vol. 71, pp. 450454, 2017.

[2] A. Rapp, F. Hopfgartner, J. Hamari, C. Linehan, and F. Cena, "Strengthening gamification studies: current trends and future opportunities of gamification research," International Journal of Human-Computer Studies, vol. 127, pp. 1-6, 2019.

[3] J. Martí-Parreño, E. Méndez-Ibáñez, and A. Alonso-Arroyo, "The use of gamification in education: a bibliometric and text mining analysis," Journal of Computer Assisted Learning, vol. 32, no. 6, pp. 663-676, 2016.

[4] D. Dicheva, C. Dichev, G. Agre, and G. Angelova, "Gamification in education: a systematic mapping study," Journal of Educational Technology and Society, vol. 18, no. 3, 2015.

[5] S. Subhash and E. A. Cudney, "Gamified learning in higher education: a systematic review of the literature," Computers in Human Behavior, vol. 87, pp. 192-206, 2018.

[6] A. Botra, M. Rerselman, and M. Ford, "Gamification beyond badges," in Proceedings of the 2014 IST-Africa Conference Proceedings, pp. 1-10, Pointe aux Piments, Mauritius, May 2014.

[7] T. A. Papp and A. Theresa, "Gamification effects on motivation and learning: application to primary and college students," International Journal for Cross-Disciplinary Subjects in Education, vol. 8, no. 3, pp. 3193-3201, 2017.

[8] A. Vaibhav and P. Gupta, "Gamification of MOOCs for increasing user engagement," in Proceedings of the 2014 IEEE International Conference on MOOC, Innovation and Technology in Education (MITE), pp. 290-295, Patiala, India, December 2014.

[9] I. Alomari, H. Al-Samarraie, and R. Yousef, "The role of gamification techniques in promoting student learning: a review and synthesis," Journal of Information Technology Education: Research, vol. 18, pp. 395-417, 2019.

[10] S. Chin, "Mobile technology and Gamification: the future is now!" in Proceedings of the 2014 Fourth International Conference on Digital Information and Communication 
Technology and Its Applications (DICTAP), pp. 138-143, Bangkok, Thailand, May 2014.

[11] R. Van Roy and B. Zaman, "Need-supporting gamification in education: an assessment of motivational effects over time," Computers \& Education, vol. 127, pp. 283-297, 2018.

[12] V. Uskov and B. Sekar, "Gamification of software engineering curriculum," in Proceedings of the 2014 IEEE Frontiers in Education Conference (FIE) Proceedings, pp. 1-8, Madrid, Spain, October 2014.

[13] D. Rojas, B. Cowan, B. Kapralos, and A. Dubrowski, "Gamification and health professions education," in Proceedings of the 2014 IEEE Games Media Entertainment, pp. 1-2, Toronto, Canada, October 2014.

[14] D. Gooch, A. Vasalou, and L. Benton, "Exploring the use of a gamification platform to support students with dyslexia," in Proceedings of the 2015 6th International Conference on Information, Intelligence, Systems and Applications (IISA), pp. 1-6, Corfu, Greece, July 2015.

[15] T.-L. Wang and Y.-F. Tseng, "An empirical study: develop and evaluation a mobile serious game on environmental education," in Proceedings of the 9th International Conference on Computer Science \& Education, pp. 311-315, Vancouver, Canada, August 2014.

[16] D. Lamprinou and F. Paraskeva, "Gamification design framework based on SDT for student motivation," in Proceedings of the 2015 International Conference on Interactive Mobile Communication Technologies and Learning (IMCL), pp. 406-410, Thessaloniki, Greece, November 2015.

[17] M. Ciolacu, A. F. Tehrani, R. Beer, and H. Popp, "Education 4.0-fostering student's performance with machine learning methods," in Proceedings of the 2017 IEEE 23rd International Symposium for Design and Technology in Electronic Packaging (SIITME), pp. 438-443, Constanta, Romania, October 2017.

[18] I. Lykourentzou, I. Giannoukos, V. Nikolopoulos, G. Mpardis, and V. Loumos, "Dropout prediction in e-learning courses through the combination of machine learning techniques," Computers \& Education, vol. 53, no. 3, pp. 950-965, 2009.

[19] K. Nand, N. Baghaei, J. Casey, B. Barmada, F. Mehdipour, and H. N. Liang, "Engaging children with educational content via Gamification," Smart Learning Environments, vol. 6, no. 1, p. 6, 2019.

[20] P. Buckley and E. Doyle, "Individualising gamification: an investigation of the impact of learning styles and personality traits on the efficacy of gamification using a prediction market," Computers \& Education, vol. 106, pp. 43-55, 2017.

[21] B. Marques and K. Nixon, "The gamified grid: possibilities for utilising game-based motivational psychology to empower the smart social grid," in Proceedings of the 2013 Africon, pp. 1-5, Pointe aux Piments, Mauritius, September 2013.

[22] F. L. Law, Z. M. Kasirun, and C. K. Gan, "Gamification towards sustainable mobile application," in Proceedings of the 2011 Malaysian Conference in Software Engineering, pp. 349-353, Johor Bahru, Malaysia, December 2011.

[23] P. Liu and Z. Peng, "Gamification interaction design of online education," in Proceedings of the 2013 2nd International Symposium on Instrumentation and Measurement, Sensor Network and Automation (IMSNA), pp. 95-101, Toronto, Canada, December 2013.

[24] A. Mathrani, S. Christian, and A. Ponder-Sutton, "PlayIT: Game based learning approach for teaching programming concepts," Journal of Educational Technology and Society, vol. 19, no. 2, pp. 5-17, 2016.

[25] B. S. Akpolat and W. Slany, "Enhancing software engineering student team engagement in a high-intensity extreme programming course using gamification," in Proceedings of the 2014 IEEE 27th Conference on Software Engineering Education and Training (CSEE\&T), pp. 149-153, Klagenfurt, Austria, April 2014.

[26] L. da Rocha Seixas, A. S. Gomes, and I. J. de Melo Filho, "Effectiveness of gamification in the engagement of students," Computers in Human Behavior, vol. 58, pp. 48-63, 2016.

[27] C. S. G. González and A. M. Carreño, "Methodological proposal for gamification in the computer engineering teaching," in Proceedings of the 2014 International Symposium on Computers in Education (SIIE), pp. 29-34, Logrono, Spain, November 2014.

[28] A. Mora, D. Riera, C. Gonzalez, and J. Arnedo-Moreno, "A literature review of gamification design frameworks," in Proceedings of the 20157 th International Conference on Games and Virtual Worlds for Serious Applications (VS-Games), pp. 1-8, Skovde, Sweden, September 2015.

[29] M. Sanmugam, Z. Abdullah, and N. M. Zaid, "Gamification: cognitive impact and creating a meaningful experience in learning," in Proceedings of the 2014 IEEE 6th Conference on Engineering Education (ICEED), pp. 123-128, Kuala Lumpur, Malaysia, December 2014.

[30] A. D. Cahyani, "Gamification approach to enhance students engagement in studying language course," MATEC Web of Conferences, vol. 58, p. 03006, 2016.

[31] S. N. M. Mohamad, N. Sazali, and M. Salleh, "Gamification approach in education to increase learning engagement," International Journal of Humanities, Arts and Social Sciences, vol. 4, pp. 22-32, 2018.

[32] C. M. Bondoc and T. G. Malawit, "Classifying relevant video tutorials for the school's learning management system using support vector machine algorithm," Global Journal of Engineering and Technology Advances, vol. 2, no. 3, pp. 001-009, 2020.

[33] T. Sangeetha and G. M. Amalanathan, "Outlier detection in neutrosophic sets by using rough entropy based weighted density method," CAAI Transactions on Intelligence Technology, vol. 5, no. 2, pp. 121-127, 2020.

[34] K. T. Chui, D. C. L. Fung, M. D. Lytras, and T. M. Lam, "Predicting at-risk university students in a virtual learning environment via a machine learning algorithm," Computers in Human Behavior, vol. 107, Article ID 105584, 2020.

[35] J.-Y. Wu, Y.-C. Hsiao, and M.-W. Nian, "Using supervised machine learning on large-scale online forums to classify course-related Facebook messages in predicting learning achievement within the personal learning environment," Interactive Learning Environments, vol. 28, no. 1, pp. 65-80, Jan. 2020.

[36] Z. Ali and T. Mahmood, "Complex neutrosophic generalised dice similarity measures and their application to decision making," CAAI Transactions on Intelligence Technology, vol. 5, no. 2, pp. 78-87, 2020.

[37] H. S. Pannu, D. Singh, and A. K. Malhi, "Improved particle swarm optimization based adaptive neuro-fuzzy inference system for benzene detection," CLEAN-Soil, Air, Water, vol. 46, no. 5, Article ID 1700162, 2018.

[38] U. Jayasinghe and A. Dharmaratne, "Game based learning vs. gamification from the higher education students' perspective," in Proceedings of 2013 IEEE International Conference on Teaching, Assessment and Learning for Engineering (TALE), pp. 683-688, Bali, Indonesia, August 2013.

[39] R. S. Alsawaier, "Research trends in the study of gamification," The International Journal of Information and Learning Technology, vol. 36, no. 5, pp. 373-380, 2019. 
[40] A. Ohno, T. Yamasaki, and K.-I. Tokiwa, "A discussion on introducing half-anonymity and gamification to improve students' motivation and engagement in classroom lectures," in Proceedings of the 2013 IEEE Region 10 Humanitarian Technology Conference, pp. 215-220, Sendai, Japan, August 2013.

[41] C. Zhu, W. Yan, X. Cai, S. Liu, T. H. Li, and G. Li, "Neural saliency algorithm guide bi-directional visual perception style transfer," CAAI Transactions on Intelligence Technology, vol. 5, no. 1, pp. $1-8,2020$

[42] E. Rossiou and T. Hainey, "An analysis of the motivations for playing computer games in a secondary education context: a comparison with higher education," in Proceedings of the European Conference on Games Based Learning, p. 518, Athens, Greece, October 2011.

[43] H. S. Pannu, D. Singh, and A. K. Malhi, "Multi-objective particle swarm optimization-based adaptive neuro-fuzzy inference system for benzene monitoring," Neural Computing and Applications, vol. 31, no. 7, pp. 2195-2205, 2019.

[44] M. Urh, G. Vukovic, E. Jereb, and R. Pintar, "The model for introduction of gamification into e-learning in higher education," Procedia-Social and Behavioral Sciences, vol. 197, no. 25, pp. 388-397, 2015.

[45] G. I. Bíró, "Didactics 2.0: a pedagogical analysis of gamification theory from a comparative perspective with a special view to the components of learning," Procedia-Social and Behavioral Sciences, vol. 141, pp. 148-151, 2014.

[46] R. Pinter, Č. S. Maravić, S. M. Čisar, Z. Balogh, and H. Manojlović, "Enhancing higher education student class Attendance through gamification," Acta Polytechnica Hungarica, vol. 17, no. 2, pp. 13-33, 2020. 